\title{
Radiopharmacokinetic Modelling and Radiation Dose Assessment of 223ra Used for Treatment of Metastatic Castration Resistant Prostate Cancer
}

\section{Vera Höllriegl}

Helmholtz Zentrum Munchen Deutsches Forschungszentrum fur Umwelt und Gesundheit

Nina Petoussi-Henss

Helmholtz Zentrum Munchen Deutsches Forschungszentrum fur Umwelt und Gesundheit

Juan Camilo Ocampo Ramos

INSERM

Wei Bo Li ( $\nabla$ wli@helmholtz-muenchen.de)

Helmholtz Zentrum München https://orcid.org/0000-0002-9802-4400

Original research

Keywords: radiopharmaceutical, biokinetic models, 223Ra, internal dose, radionuclide therapy

Posted Date: July 16th, 2020

DOI: https://doi.org/10.21203/rs.3.rs-41574/v1

License: (a) (i) This work is licensed under a Creative Commons Attribution 4.0 International License.

Read Full License 


\title{
Radiopharmacokinetic modelling and radiation dose assessment of ${ }^{223} \mathrm{Ra}$ used for treatment of metastatic castration resistant prostate cancer
}

\author{
Vera Höllriegl ${ }^{1}$, Nina Petoussi-Henss ${ }^{1}$, Juan Camilo Ocampo Ramos ${ }^{2}$, Wei Bo Li ${ }^{1 \text { * }}$ \\ ${ }^{1}$ Helmholtz Zentrum München, German Research Center for Environmental Health, \\ Institute of Radiation Medicine, Ingolstädter Landstrasse 1, 85764 Neuherberg, Germany \\ ${ }^{2}$ Centre de Recherche en Cancérologie de Toulouse, UMR 1037, INSERM, Toulouse, France \\ *e-mail: wli@helmholtz-muenchen.de; phone: +49 (0)89 31873314
}

\section{Abstract}

Purpose Ra-223-Dichloride $\left({ }^{223} \mathrm{Ra}\right.$, Xofigo $\left.\AA\right)$ is used for treatment of patients suffering from castrationresistant metastatic prostate cancer. The objective of this work was to apply the most recent biokinetic model for radium and its progeny and dosimetric framework developed by the International Commission on Radiological Protection (ICRP) and to show their radiopharmacokinetic behaviour. Organ absorbed and equivalent doses after intravenous injection of ${ }^{223} \mathrm{Ra}$ were estimated and compared to clinical data and other modelling study.

Methods The most recent ICRP systemic biokinetic model of ${ }^{223} \mathrm{Ra}$ and its progeny as well as the ICRP human alimentary tract model were applied for the radiopharmacokinetic modelling of Xofigo® biodistribution in patients after bolus administration. Independent kinetics was assumed for the progeny of ${ }^{223} \mathrm{Ra}$. The time activity curves for ${ }^{223} \mathrm{Ra}$ were modelled and the time integrated activity coefficients, $\tilde{a}\left(r_{S}, T_{D}\right)$, in the source regions for each progeny were determined. For estimating the organ absorbed doses, the Specific Absorbed Fractions (SAF) and dosimetric framework of ICRP were used together with the aforementioned $\tilde{a}\left(r_{S}, T_{D}\right)$ values to estimate the organ absorbed and equivalent doses.

Results The distribution of ${ }^{223} \mathrm{Ra}$ after injection showed a rapid plasma clearance and a low urinary excretion. Main elimination was via faeces. Bone retention was found to be about $30 \%$ at $4 \mathrm{~h}$ postinjection. Similar tendencies were observed in clinic trials. The highest absorbed dose coefficients were found for bone endosteum, liver, and red marrow, followed by kidneys and colon.

Conclusion The biokinetic modelling of ${ }^{223} \mathrm{Ra}$ and its progeny may help to predict their distributions in patients after administration of Xofigo $\AA^{\circledR}$. The organ dose coefficients of this work showed some variation to the values from clinical studies and of a previous compartmental modelling study. The dose to the bone endosteum was found to be lower by a factor of ca. 3 than previously estimated.

Keywords radiopharmaceutical, biokinetic models, ${ }^{223} \mathrm{Ra}$, internal dose, radionuclide therapy 


\section{Introduction}

Worldwide, prostate cancer is the second most frequent cancer in men [1]. In 2013, ${ }^{223} \mathrm{Ra}$-dichloride $\left({ }^{223} \mathrm{Ra}\right.$, Xofigo®, Bayer) was approved by the US Food and Drug Administration (FDA) and by the European Commission as a tolerated radiopharmaceutical for treatment of patients suffering from castration-resistant prostate cancer with bone metastases and no visceral metastases [2]. The bone metastases can result in severe bone pain and other symptoms, like pathologic fractures, spinal cord compression or myelosuppression [3]. As ${ }^{223}$ Ra behaves like calcium after its intravenous injection into the human body, its main target is the bone, at areas of active bone formation, thereby forming complexes with the bone mineral hydroxyapatite. ${ }^{223} \mathrm{Ra}$ is an alpha-emitter (physical half-life 11.4 days) with a high linear energy transfer $(80 \mathrm{keV} / \mu \mathrm{m})$ which may lead to a high frequency of doublestrand DNA breaks in tumour cells; this may result in a highly localized cytotoxic effect to tumour cell death. The short alpha particle path range $(<100 \mu \mathrm{m})$ may minimize damage to the surrounding normal tissue. After intravenous administration of ${ }^{223} \mathrm{Ra}$, its bone-seeking and alpha-particle emitting properties may reduce bone pain, thereby improving the quality of life of the patients. The trial has proven that the treatment with ${ }^{223} \mathrm{Ra}$ extend the overall survival rate of patients to 3.6 months [4]. ${ }^{223} \mathrm{Ra}$ decays via six short-lived daughter nuclides into the stable lead isotope ${ }^{207} \mathrm{~Pb}$; the total emitted energy is $28.2 \mathrm{MeV}$, of which $95.3 \%$ is from alpha emission, $3.6 \%$ from beta and $1.1 \%$ from gamma emission (Table 1). Although the photon yield is low, gamma camera imaging is feasible. In the last years, several clinical trials using $\mathrm{Xofigo} \circledast$ were performed to demonstrate the pharmacokinetic behaviour of ${ }^{223} \mathrm{Ra}$ in the human body after its intravenous injection, and to estimate organ absorbed doses in radiation-sensitive organs and tissues, such as bone surface or red marrow [5-8]. In 2017, the International Commission on Radiation Protection (ICRP) published new biokinetic data of ${ }^{223} \mathrm{Ra}$ and its progeny in ICRP Publication 137 [9]. The improved systemic model of radium is a modification of the previous model of ICRP Publication 67 [10]. The objective of this work is to apply the new biokinetic model for radium and its progeny, follow their distribution in the human body and compare the model prediction with data of patients reported during four clinical trials reported at $[5,7,8,11]$. Moreover, the organ absorbed dose coefficients after intravenous injection of ${ }^{223} \mathrm{Ra}$ were estimated according to the ICRP/MIRD schema for radiopharmaceutical dosimetry [12] by applying the latest SAF values of ICRP calculated for the male reference adult according to the ICRP methodology [13]. 
The results obtained in this study were compared with organ absorbed doses estimated via imaging data of patients, and additionally with a compartmental modelling study of other authors who used the biokinetic modelling of ICRP Publication 67 and earlier dosimetric methods.

Table 1 Decay chain of ${ }^{223} \mathrm{Ra}$ and its progeny to stable ${ }^{207} \mathrm{~Pb}$ (from [14])

\begin{tabular}{ccccc}
\hline Radionuclide & $\begin{array}{c}\text { Decay } \\
\text { mode }\end{array}$ & $\begin{array}{c}\text { Abundance } \\
(\%)\end{array}$ & Half-life & Decay constants $\left(\mathrm{d}^{-1}\right)$ \\
\hline${ }^{223} \mathrm{Ra} \rightarrow{ }^{219} \mathrm{Rn}$ & $\alpha$ & 100 & 11.43 days & 0.0606 \\
${ }^{219} \mathrm{Rn} \rightarrow{ }^{215} \mathrm{Po}$ & $\alpha$ & 100 & $3.96 \mathrm{~s}$ & 15123.2112 \\
${ }^{215} \mathrm{Po} \rightarrow{ }^{211} \mathrm{~Pb}$ & $\alpha$ & 100 & $1.78 \mathrm{~ms}$ & 33644896.8541 \\
${ }^{211} \mathrm{~Pb} \rightarrow{ }^{211} \mathrm{Bi}$ & $\beta^{-}$ & 100 & $36.1 \mathrm{~min}$ & 27.6490 \\
${ }^{211} \mathrm{Bi} \rightarrow{ }^{211} \mathrm{Po}$ & $\beta^{-}$ & 0.276 & $2.14 \mathrm{~min}$ & 1.2873 \\
${ }^{211} \mathrm{Bi} \rightarrow{ }^{20 /} \mathrm{Tl}$ & $\alpha$ & 99.72 & $2.14 \mathrm{~min}$ & 465.1107 \\
${ }^{211} \mathrm{Po} \rightarrow{ }^{207} \mathrm{~Pb}$ & $\alpha$ & 100 & $0.516 \mathrm{~s}$ & 116061.8534 \\
${ }^{20 /} \mathrm{Tl} \rightarrow{ }^{20 /} \mathrm{Pb}$ & $\beta^{-}$ & 100 & $4.77 \mathrm{~min}$ & 209.2519 \\
\hline
\end{tabular}

\section{Materials and methods}

Radiopharmacokinetic modelling

ICRP Publication 137 [9] reports new biokinetic data of ${ }^{223}$ Ra and its progeny. Figure 1 shows the systemic biokinetic model of ${ }^{223} \mathrm{Ra}$, consisting of compartments representing the Skeleton, Blood, Liver, Kidneys with the excretion pathway to Urine, and with connection to the Gastro-intestinal Tract, and the excretion pathway via Faeces. Additionally, a compartment of Other Soft Tissue, subdivided into ST0, ST1, and ST2 is linked to the transfer compartment Blood. The Other Soft Tissue comprises all soft tissues, which were not explicitly defined in the systemic model of ${ }^{223} \mathrm{Ra}$. The compartments Skeleton, Liver and Kidneys, and the Large Intestine are also subdivided. The Skeleton is compartmentalised into the bone surface and bone volume; the latter is again divided into the nonexchangeable (nonexch) and exchangeable (exch) part. The Large Intestine includes the Right Colon $(R C)$, Left Colon (LC) and Recto Sigmoid (RS) according to the Human Alimentary Tract Model 
(HATM) [15]. Each compartment is linked through the decay constant of ${ }^{223}$ Ra with the corresponding compartments of the next progeny ${ }^{219} \mathrm{Rn}$.

As the biokinetics of the ${ }^{223} \mathrm{Ra}$ progeny are independent from the parent nuclide ${ }^{223} \mathrm{Ra}$, their transfer rates and their compartment structures are not necessarily identical to those of their parent. Compartments representing the organs/tissues Spleen, Skin, Gonads, Trabecular Marrow and Cortical Marrow are specific for some biokinetic models of the daughter nuclides of ${ }^{223} \mathrm{Ra}$. Therefore, prior to the whole biokinetic modelling of ${ }^{223} \mathrm{Ra}$ and its progeny, and according to ICRP 137 [9], each biokinetic model of the nuclides in the radium decay chain (including ${ }^{223} \mathrm{Ra}$ ) was expanded for the five complementary compartments mentioned above; all transfer rates were taken from ICRP 137 [9]. For the biokinetic model of ${ }^{223} \mathrm{Ra}$ the transfer rates from the Blood compartment to the newly established compartments of Trabecular Marrow, Cortical Marrow, Spleen, Skin and Testes, were calculated from the corresponding transfer rate of the Other Soft Tissue compartment by considering their massfraction. The masses of the above mentioned organs and tissues were taken from ICRP [13].The transfer rate from the blood compartment to the Other Soft Tissue was reduced accordingly.

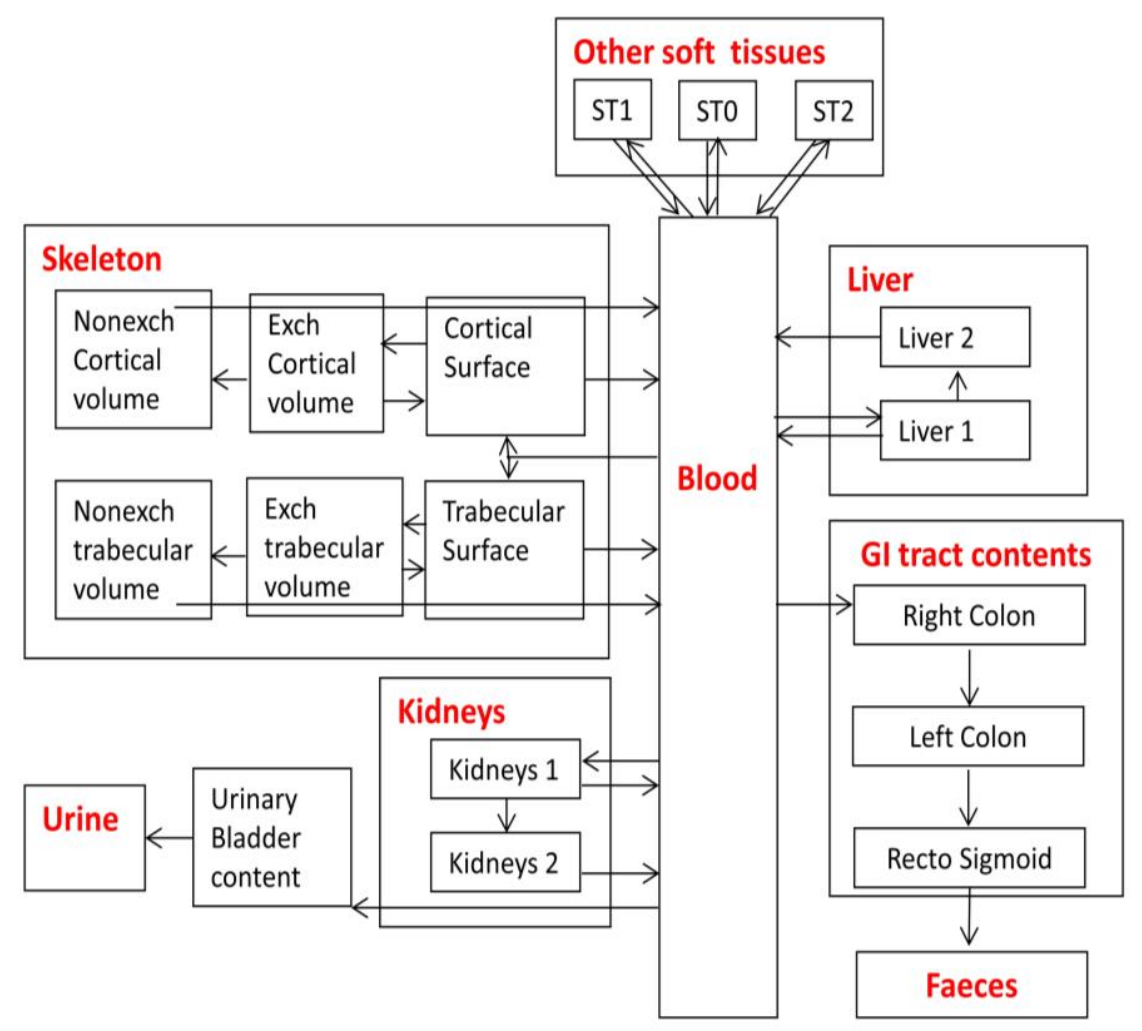

Fig. 1 Systemic model of ${ }^{223} \mathrm{Ra}$, according to ICRP 137 (2017) [9] 
Implementation of the complete compartmental model in SAAM II software

The biokinetics of ${ }^{223} \mathrm{Ra}$ and its progeny were described by a system of first-order linear ordinary differential equations, which were numerically solved by using the commercial software package SAAM II [16]. All model parameters (compartmental structures and transfer rates) of ${ }^{223} \mathrm{Ra}$ and its daughter nuclides $\left({ }^{219} \mathrm{Rn},{ }^{215} \mathrm{Po},{ }^{211} \mathrm{~Pb},{ }^{211} \mathrm{Bi},{ }^{211} \mathrm{Po}\right.$, and $\left.{ }^{207} \mathrm{TI}\right)$ were inserted into the SAAM II software. The equivalent compartments of each model element were connected through their decay constants (see Table 1); a period of $168 \mathrm{~h}$ after injection was assumed to follow the time-dependent distribution of ${ }^{223} \mathrm{Ra}$ and its progeny in the organs and tissues after a simulated injection, as well as the excretion route. For dose assessment, the time-integrated activity coefficients were calculated as the area under the curve (AUC) up to a time period of 1000 days after injection, because beyond this time the $A \cup C$ in each organ and tissue remain unchanged.

Calculation of absorbed and equivalent dose coefficients

The determination of internal doses can be performed by mathematical calculations using standardised biokinetic and dosimetric models. The ICRP and the Committee on Medical Internal Radiation Dose (MIRD) of Society of Nuclear Medicine generalised the schema for the calculation of absorbed dose and effective dose coefficients to the patients from administered radiopharmaceuticals [12]. The absorbed dose coefficient is calculated by the time integrated activity coefficients $\tilde{a}\left(r_{S}, T_{D}\right)$ in source organs, and S-values, specific to the radionuclide and computational phantom used for the calculation, according to the following equations:

$d\left(r_{T}, T_{D}\right)=\sum_{r_{S}} \tilde{a}\left(r_{S}, T_{D}\right) S\left(r_{T} \leftarrow r_{S}\right)$

$S\left(r_{T} \leftarrow r_{S}\right)=\sum_{i} E_{i} Y_{i} \frac{\phi\left(r_{T} \leftarrow r_{S}, E_{i}\right)}{M_{T}}=\sum_{i} E_{i} Y_{i} \Phi\left(r_{T} \leftarrow r_{S}, E_{i}\right)$

Where $d\left(r_{T}, T_{D}\right)$ is the absorbed dose coefficient in organ $T ; \tilde{a}\left(r_{S}, T_{D}\right)$ is the time-integrated activity coefficient in source organ $r_{S}$ over dose-integration period $T_{D}$ per unit administered activity;

$S\left(r_{T} \leftarrow r_{S}\right)$ is the mean absorbed dose rate to target tissue $r_{T}$ per unit activity present in source tissue $r_{S}$ and is called $S$ value. $E_{i}$ is the mean (or individual) energy of the ith nuclear transition; $Y_{i}$ is 
yield of ith nuclear transitions per nuclear transformation. $\phi\left(r_{T} \leftarrow r_{S}, E_{i}\right)$ is the absorbed fraction (defined as the fraction of radiation energy $E_{i}$ emitted within the source tissue $r_{S}$ at time $t$ that is absorbed in the target tissue $r_{\mathrm{T}}$ ), and $M_{\mathrm{T}}$ is the mass of the target tissue $r_{\mathrm{T}}$ in the reference individual; $\Phi\left(r_{T} \leftarrow r_{S}, E_{i}\right)$ is the SAF value which is defined as the ratio of the absorbed fraction and the target mass $M_{T}$.

The equivalent dose coefficient $h\left(r_{T}, T_{D}\right)$ is defined as:

$h\left(r_{T}, T_{D}\right)=\sum_{R} w_{R} d\left(r_{T}, T_{D}\right)$

Where $w_{R}$ is the radiation-weighting factor for radiation type $R$, and $d\left(r_{T}, T_{D}\right)$ is the contribution of radiation type $R$ to the mean absorbed dose coefficient in target tissue $r_{T}$. For alpha particles, ICRP [17] recommends a radiation-weighting factor of 20 . This value is valid for stochastic (cancer) risks and not for tissue reactions. However, in addition, a radiation-weighting factor $\mathrm{w}_{\mathrm{R}}$ of 5 has been used in this work, as the MIRD Committee [18] suggests this value for possible tissue reactions originating from alpha particles.

SAF values are calculated with Monte Carlo methods following the transport of radiation in anthropomorphic computational phantoms. For this work, the SAFs were taken from the ICRP Publication 133 [13] which provides reference values for internally emitted monoenergetic photons, electrons, alpha particles, fission-spectrum neutrons, as well as several improved dosimetric features. The SAFs were calculated for the ICRP adult reference voxel phantoms [19]. For bone dosimetry and photons and neutrons, dose response functions were implemented. Furthermore, electron SAFs of bone surface as source organ were based on microCT of spongiosa structures. For some small tissues beyond the resolution of the voxel phantoms, other detailed models were used to define alpha and electron SAFs values as for the alimentary tract and respiratory tract. Another feature of the ICRP SAFs is that blood as source organ is used instead of body tissues, which were previously used as surrogate for blood. More information on the ICRP internal dosimetry framework can be found at [13].

Time integrated activity coefficients for each radionuclide and each source organ were calculated and are listed in Table 2. An in-house dose computational software [20,21] was used which incorporates the activity coefficients, the SAF values and the most recent nuclear decay data of ICRP Publication 107 [14] and performs absorbed and equivalent dose calculations for photons, electrons and alpha 
particles of the desired radionuclide. The absorbed dose to a target region was estimated by summing the contributions from the decay of the daughter products of ${ }^{223} \mathrm{Ra}$ i.e. ${ }^{219} \mathrm{Rn},{ }^{215} \mathrm{Po},{ }^{211} \mathrm{~Pb},{ }^{211} \mathrm{Bi},{ }^{211} \mathrm{Po}$, and ${ }^{207} \mathrm{TI}$.

Table 2 Time integrated activity coefficients for each radionuclide and each source organ (in $\mathrm{h}$ )

\begin{tabular}{|c|c|c|c|c|c|c|c|}
\hline Source organs & ${ }^{223} \mathrm{Ra}$ & ${ }^{219} \mathrm{Rn}$ & ${ }^{215} \mathrm{Po}$ & ${ }^{211} \mathrm{~Pb}$ & ${ }^{211} \mathrm{Bi}$ & ${ }^{211} \mathrm{Po}$ & ${ }^{20 /} \mathrm{TI}$ \\
\hline Blood & 0.90 & 0.52 & 1.04 & 0.49 & 0.34 & 0.0009 & 0.20 \\
\hline Other tissues & 6.95 & 6.93 & 5.36 & 7.07 & 7.15 & 0.02 & 7.54 \\
\hline Cortical bone surface & 10.15 & 10.09 & 10.09 & 9.81 & 9.81 & 0.03 & 9.68 \\
\hline Cortical bone volume & 8.64 & 8.64 & 8.64 & 8.81 & 8.81 & 0.02 & 8.77 \\
\hline \multicolumn{8}{|l|}{ Trabecular bone } \\
\hline surface & 12.01 & 11.94 & 11.94 & 11.61 & 11.61 & 0.03 & 11.46 \\
\hline \multicolumn{8}{|l|}{ Trabecular bone } \\
\hline volume & 17.90 & 17.90 & 17.90 & 18.10 & 11.61 & 0.05 & 18.05 \\
\hline Kidneys & 0.65 & 0.35 & 0.65 & 0.69 & 0.71 & 0.002 & 0.71 \\
\hline \multicolumn{8}{|l|}{ Urinary bladder } \\
\hline content & 0.05 & 0.05 & 0.05 & 0.05 & 0.07 & 0.00018 & 0.06 \\
\hline Liver & 5.11 & 5.18 & 5.18 & 5.25 & 5.27 & 0.02 & 5.20 \\
\hline Cortical Marrow & 0.04 & 0.04 & 0.04 & 0.04 & 0.04 & 0.0001 & 0.04 \\
\hline Skin & 0.16 & 0.16 & 0.16 & 0.16 & 0.16 & 0.0004 & 0.17 \\
\hline Trabecular Marrow & 0.45 & 0.45 & 0.45 & 0.46 & 0.46 & 0.0013 & 0.45 \\
\hline Spleen & 0.007 & 0.007 & 0.007 & 0.008 & 0.008 & 0.00002 & 0.008 \\
\hline Testes & 0.002 & 0.002 & 0.002 & 0.002 & 0.002 & 0.000004 & 0.002 \\
\hline Right Colon content & 9.53 & 9.53 & 9.53 & 8.90 & 8.86 & 0.024 & 8.80 \\
\hline Left Colon content & 9.25 & 9.25 & 9.25 & 9.22 & 9.22 & 0.03 & 9.19 \\
\hline \multicolumn{8}{|l|}{ Recto Sigmoid } \\
\hline content & 8.98 & 8.98 & 8.98 & 8.99 & 8.99 & 0.03 & 8.97 \\
\hline
\end{tabular}




\section{Results}

Fig. 2 shows the time-dependent distribution of ${ }^{223} \mathrm{Ra}$ after a simulated intravenous administration. The plasma clearance of ${ }^{223} \mathrm{Ra}$ was very fast, $2 \mathrm{~h}$ after injection about $2.5 \%$ of the injected activity remained in the plasma and after $24 \mathrm{~h}$ post-injection less than $1 \%$ was left in the plasma. Initial bone uptake of ${ }^{223} \mathrm{Ra}$ within $4 \mathrm{~h}$ post-injection was about $30 \%$, primarily into the bone surface. A slow uptake of up to $6 \%$ of ${ }^{223} \mathrm{Ra}$ followed into the bone volume (both cortical and trabecular) at $80 \mathrm{~h}$ postinjection (data not shown). While the cumulative urinary excretion was low (ca. $2 \%$ ), the cumulative excretion into faeces amounted to about $51 \%$ after $3 \mathrm{~d}$ post-injection; therefore, the main elimination of ${ }^{223} \mathrm{Ra}$, as shown in Fig. 3, was through the colon (into faeces) and not through the urinary pathway. Fig. 4 reveals a low uptake in liver, up to ca. $7 \%$ after $7 \mathrm{~h}$ post-injection, and a $2 \%$ uptake in kidneys at $2 \mathrm{~h}$ after injection. No significant distribution of ${ }^{223} \mathrm{Ra}$ was observed in other organs or tissues, neither for radium progeny. Data from four clinical trials $[5,7,8,11]$ with in total 47 patients receiving Xofigo ${ }^{\circledR}$ due to bone metastases compared to the present modelled data are also shown in Fig. 2 and 3. Table 3 summarises the modelled data, together with the clinical data showing the wide range of distribution patterns of ${ }^{223} \mathrm{Ra}$ in the human body of the patients. 


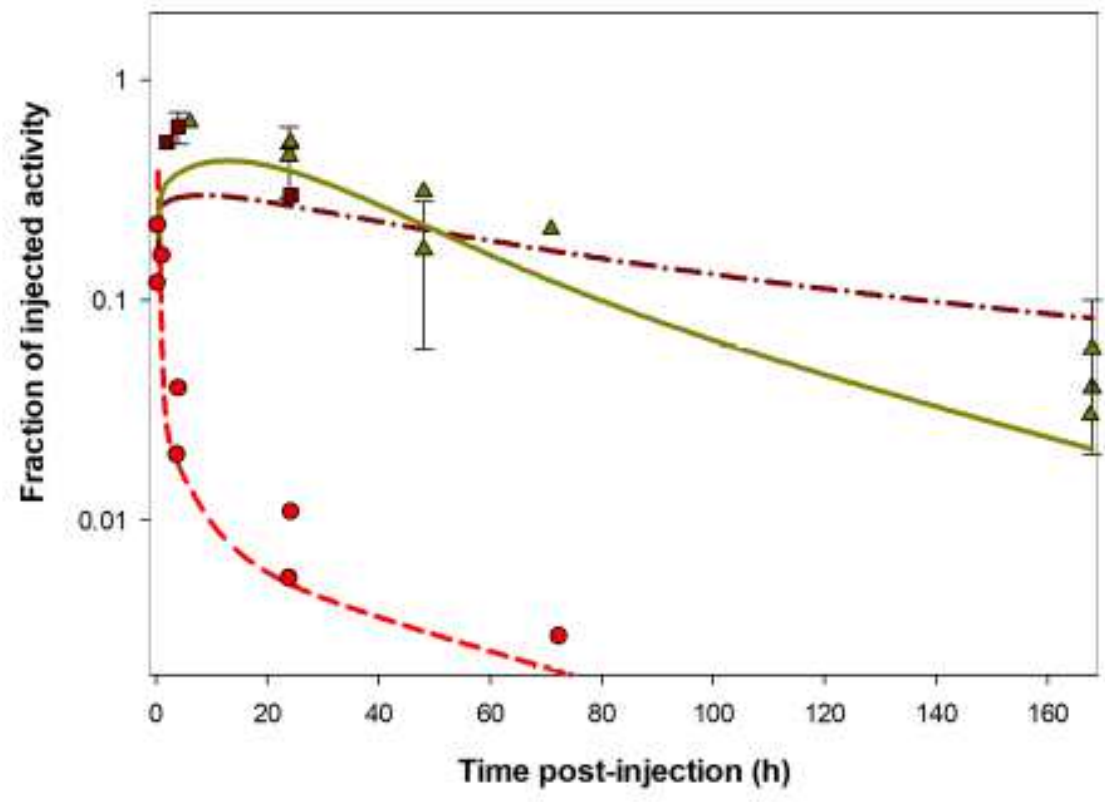

Fig. 2 Time-dependent distribution of ${ }^{223} \mathrm{Ra}$ in plasma, bone and colon after intravenous injection. Dashed Line $=$ modelled data of plasma, solid line $=$ modelled data of colon, dash-dotted line $=$ modelled data of bones. Bullets $=$ plasma data of patients, squares $=$ bone data of patients, triangles $=$ colon data of patients. Patient data from $[5,7,8,11]$ shown with median values or values of mean \pm SD. Bone indicates total bone i.e. cortical, trabecular surface, volume and marrow. 


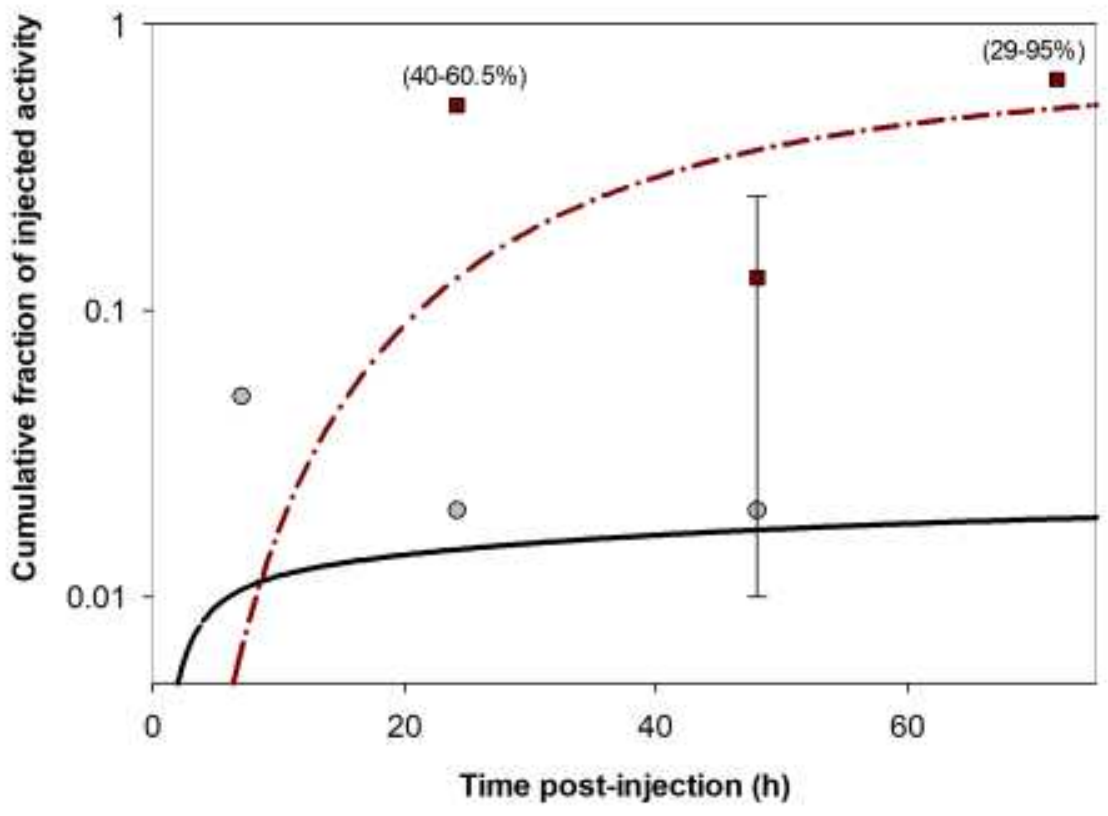

Fig. 3 Time-dependent excretion of ${ }^{223} \mathrm{Ra}$ after intravenous injection. Dash-dotted line $=$ modelled data of faeces, solid line $=$ modelled data of urine; squares $=$ faeces data of patients, bullets $=$ urine data of patients. Patient data from $[5,7,8,11]$ shown with mean values or mean $\pm S D$, or ranges (in parentheses) 


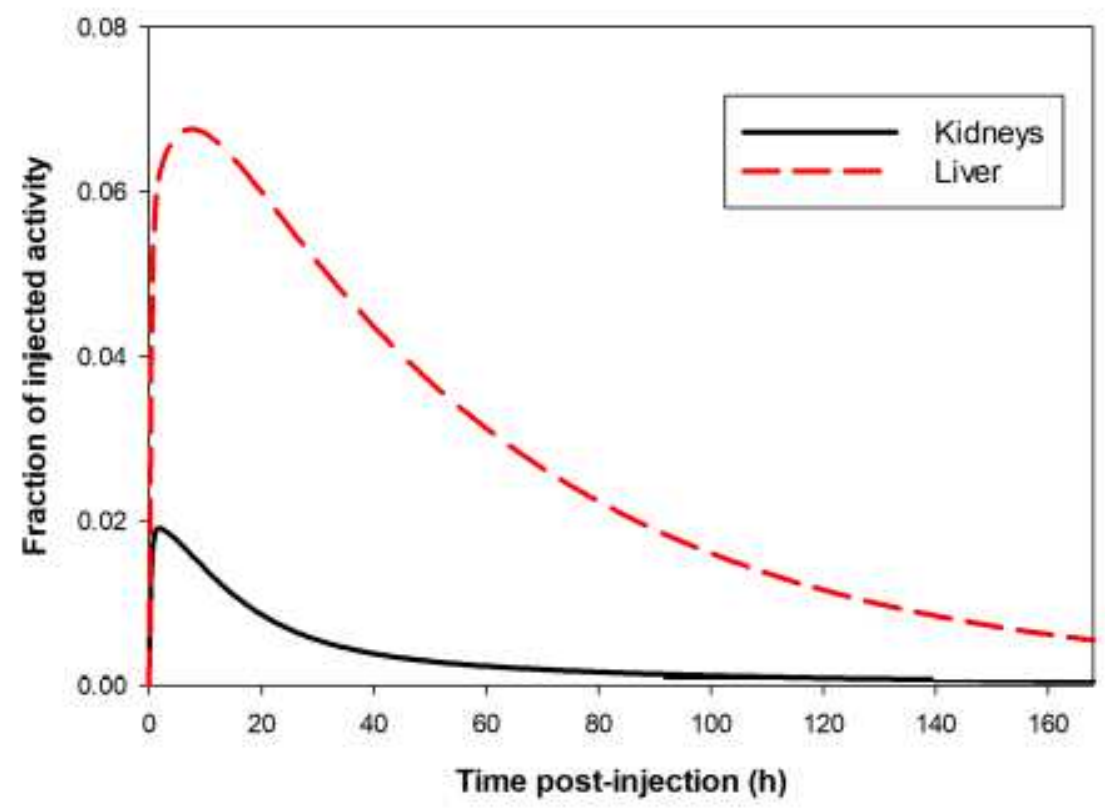

Fig. 4 Modelled time-dependent distribution of ${ }^{223} \mathrm{Ra}$ in kidneys and liver after intravenous injection

Table 3 Overview of the biodistribution of ${ }^{223} \mathrm{Ra}$ after intravenous injection in patients from four clinical trials $[6,8,9,12]$, in comparison to the modelled data of the present work; data expressed as percentage of administered ${ }^{223} \mathrm{Ra}$; values given as range, median or mean $\pm \mathrm{SD} ; \mathrm{n}=$ patient number

\begin{tabular}{|c|c|c|c|c|c|c|}
\hline & $\begin{array}{l}\text { Time post- } \\
\text { injection }\end{array}$ & $\begin{array}{l}\text { Present } \\
\text { work }\end{array}$ & $\begin{array}{l}\text { Nilsson et } \\
\text { al. [11] }\end{array}$ & $\begin{array}{l}\text { Carrasquillo et } \\
\text { al. [8] }\end{array}$ & $\begin{array}{l}\text { Chittenden et } \\
\text { al. [7] }\end{array}$ & $\begin{array}{l}\text { Yoshida et al. } \\
\text { [5] }\end{array}$ \\
\hline & & & $\mathrm{n}=25$ & $\mathrm{n}=10$ & $n=6$ & $n=6$ \\
\hline \multirow[t]{4}{*}{ Plasma } & $10-15 \min$ & 30 & 12 & & & $9-28(22)$ \\
\hline & $4 \mathrm{~h}$ & 1.9 & & $1.6-3.9(2)$ & & $1-6(4)$ \\
\hline & $24 \mathrm{~h}$ & 0.5 & $<1$ & $0.37-1.0(0.55)$ & $0.6-5.1(1.1)$ & \\
\hline & $3 d$ & 0.2 & & & & $0-0.9(0.3)$ \\
\hline \multirow[t]{2}{*}{ Bone $^{a}$} & $2 \mathrm{~h}$ & 28 & & & & $41-57$ (52) \\
\hline & $4 \mathrm{~h}$ & 29.2 & & & $61 \pm 10$ & \\
\hline Urine & $2 d$ & 1.7 & & 5 & $2 \pm 2$ & 2 \\
\hline
\end{tabular}




\begin{tabular}{|c|c|c|c|c|c|}
\hline \multirow[t]{4}{*}{ Faeces } & $1 d$ & 13 & $40-61(52)$ & & \\
\hline & $2 d$ & 36 & & $13 \pm 12$ & \\
\hline & $3 d$ & 51 & & & $29-95(64)$ \\
\hline & $7 d$ & 68 & & $60-80$ & \\
\hline \multirow[t]{2}{*}{ ULI/RC* } & $1 \mathrm{~d}$ & 12 & & $45 \pm 16$ & \\
\hline & $7 d$ & 0.6 & & $0-18(4)$ & \\
\hline \multirow[t]{2}{*}{$\mathrm{LLI} / \mathrm{LC}^{* *}$} & $2 d$ & 7.3 & & $17 \pm 11$ & \\
\hline & $7 d$ & 0.7 & & $6 \pm 4$ & \\
\hline \multirow{6}{*}{$\begin{array}{l}\text { Gl tract/ } \\
\text { HATM }^{* \star *}\end{array}$} & $6 \mathrm{~h}$ & 41 & & & $22-85(64)$ \\
\hline & & & & & \\
\hline & $1 d$ & 39 & $50.8 \pm 7.5$ & & $32-78(52)$ \\
\hline & $2 d$ & 22 & & & 4-76 (31) \\
\hline & $3 d$ & 12 & & & $5-53(21)$ \\
\hline & $7-8 d$ & 2 & & & $0-9(3)$ \\
\hline
\end{tabular}

${ }^{a}$ Total bone i.e. surface, volume and bone marrow; *ULI/RC, upper large intestine/right colon, ** $\mathrm{LLI} / \mathrm{LC}$, lower large intestine/left colon, ${ }^{* *} \mathrm{GI}$ tract; Gastrointestinal tract (ICRP 30, [22]) representing small intestine, ULI and LLI; HATM, human alimentary tract model (HATM) [15] representing RC, LC and recto sigmoid

Absorbed and equivalent dose coefficients

From the biokinetic modelling, 17 source organs were defined: blood, cortical and trabecular bone surfaces, cortical and trabecular bone volumes, cortical and trabecular marrow, kidneys, urinary bladder content, liver, testes, spleen, skin, right colon contents, left colon contents, recto sigmoid contents, and other tissues. A table of the time integrated activity coefficients for each radionuclide and each source organ as calculated by the biokinetic model can be found in Table 2. Absorbed doses for 28 target organs were calculated. Table 4 presents organ absorbed dose coefficients (in $\mathrm{mGy} / \mathrm{MBq}$ ) for some selected organs, considering the alpha, beta and gamma contribution to the total dose. The highest doses were observed in the bone endosteum (i.e. bone surface), red marrow, liver, kidneys and colon. Table 4 also shows the values of a previous modelling study of Lassmann and 
Nosske [23] and of the clinical studies of Chittenden et al [7] and Yoshida et al. [5]. The results of the present work for bone surface and red marrow showed lower dose values (by a factor 2.3-3.4) compared to the modelling study of Lassmann and Nosske [23] and the clinical study of Yoshida et al. [5] and even lower to values of the clinical study of Chittenden et al. [7]. However, the dose coefficients for liver and kidneys were found to be much higher than those of the clinical studies. It should be noted that organ doses (or coefficients) stemming from clinical studies cannot be compared directly with compartmental modelling calculations, as a specific tumour dosimetry is not included in these models [24].

Table 4 Absorbed dose coefficients ( $\mathrm{mGy} / \mathrm{MBq}$ ) with contribution from alpha, beta and gamma radiation to the total absorbed dose, after simulated injection of ${ }^{223} \mathrm{Ra}$, in comparison to the modelling study of Lassmann and Nosske [23] and the clinical studies of Chittenden et al [7] and Yoshida et al. [5]. Values of Yoshida et al. refer to the total absorbed dose coefficients

\begin{tabular}{|c|c|c|c|c|c|c|c|c|}
\hline \multirow[b]{2}{*}{ Organ } & \multicolumn{3}{|c|}{ Present work } & \multicolumn{2}{|c|}{$\begin{array}{l}\text { Lassman and } \\
\text { Nosske [23] }\end{array}$} & \multicolumn{2}{|c|}{$\begin{array}{l}\text { Chittenden et al. } \\
\text { [7] }\end{array}$} & \multirow{2}{*}{$\begin{array}{c}\text { Yoshida et } \\
\text { al. [5] } \\
\text { Total }\end{array}$} \\
\hline & Alpha & $\begin{array}{l}\text { Beta/ } \\
\text { gamma }\end{array}$ & Total & Alpha & $\begin{array}{l}\text { Beta/ } \\
\text { gamma }\end{array}$ & Alpha & $\begin{array}{l}\text { Beta/ } \\
\text { gamma }\end{array}$ & \\
\hline Adrenals & 1.86 & 0.27 & 2.13 & 3.2 & 0.24 & & & 0.06 \\
\hline UB wall & 1.85 & 0.23 & 2.08 & 3.3 & 0.41 & 3 & $<1$ & 1.54 \\
\hline Endost-BS & 215.71 & 5.23 & 221 & 750 & 11 & 5378 & 21 & 761 \\
\hline Brain & 1.84 & 0.19 & 2.04 & 3.2 & 0.18 & & & 0.05 \\
\hline Breast & 1.85 & 0.12 & 1.96 & 3.2 & 0.16 & & & 0.02 \\
\hline Stomach wall & 1.87 & 0.25 & 2.11 & 3.2 & 0.21 & & & 0.08 \\
\hline SI wall & 1.87 & 0.25 & 2.12 & 3.2 & 0.39 & 0 & 5 & 5.42 \\
\hline Colon & 1.87 & 2.73 & 4.60 & 9.5 & 25 & 0 & 47 & 12.9 \\
\hline Kidneys & 22.15 & 1.13 & 23.3 & 3.4 & 0.24 & 6 & $<1$ & 2.00 \\
\hline Liver & 34.53 & 1.49 & 36.0 & 3.6 & 1.5 & 2 & $<1$ & 1.87 \\
\hline Lungs & 1.64 & 0.13 & 1.51 & 3.2 & 0.19 & & & 0.03 \\
\hline
\end{tabular}




\begin{tabular}{|c|c|c|c|c|c|c|c|c|}
\hline Muscle & 1.84 & 0.18 & 2.02 & 3.2 & 0.2 & & & 0.06 \\
\hline Pancreas & 1.86 & 0.29 & 2.15 & 3.2 & 0.22 & & & 0.06 \\
\hline Red marrow & 30.42 & 3.03 & 33.5 & 72 & 5.5 & 408 & 9 & 91.6 \\
\hline Skin & 0.81 & 0.07 & 0.88 & 3.2 & 0.16 & & & 0.03 \\
\hline Spleen & 1.17 & 0.14 & 1.31 & 3.2 & 0.19 & & & 0.04 \\
\hline Testes & 0.82 & 0.06 & 0.89 & 3.2 & 0.18 & & & 0.03 \\
\hline Thymus & 1.85 & 0.17 & 2.02 & 3.2 & 0.17 & & & 0.02 \\
\hline Thyroid & 1.86 & 0.13 & 1.98 & 3.2 & 0.17 & 3.2 & 0.17 & 0.03 \\
\hline
\end{tabular}

UB wall, urinary bladder wall; SI wall, small intestine wall; Endost-BS, endosteum bone surface

More than $99 \%$ of the absorbed dose in the organs is due to alpha and beta particles, emitted from ${ }^{223} \mathrm{Ra}$ and its progeny; the relative contribution of each progeny to four organs is given in Table 5 . Similar contributions of each ${ }^{223}$ Ra progeny to the bone lesions was reported by Murray et al. [25].

Table 5 Relative contribution of ${ }^{223} \mathrm{Ra}$ and its progeny to the total absorbed dose of bone surface, red marrow, liver, and kidneys (in \%)

\begin{tabular}{lccccccc}
\hline Isotopes & ${ }^{223} \mathrm{Ra}$ & ${ }^{219} \mathrm{Rn}$ & ${ }^{215} \mathrm{Po}$ & ${ }^{211} \mathrm{~Pb}$ & ${ }^{211} \mathrm{Bi}$ & ${ }^{211} \mathrm{Po}$ & ${ }^{207} \mathrm{TI}$ \\
\hline Organ & & & & & & & \\
\hline Red marrow & 20 & 24 & 27 & 4 & 21 & 0 & 4 \\
Endost-BS & 22 & 26 & 28 & 1 & 23 & 0 & 1 \\
Liver & 21 & 24 & 23 & 3 & 22 & 0 & 2 \\
Kidneys & 23 & 15 & 30 & 2 & 28 & 0 & 2 \\
\hline Endost-BS, endosteum bone surface & & & & & & & \\
\hline
\end{tabular}


Table 6 presents the equivalent dose coefficients for selected organs. Two different radiation weighting factors, $w_{R}$, for alpha particles were used: $a w_{R}$ of 20 according to ICRP [17], which is the value valid for stochastic (cancer) risks; and $a w_{R}$ of 5 , the value that the MIRD Committee [18] suggests for possible deterministic biological effects originating from therapies with alpha emitters.

Table 6 Equivalent dose coefficients using two different radiation weighting factors of $\mathrm{w}_{\mathrm{R}}=5$, and 20 , respectively

\begin{tabular}{lcc}
\hline Organ & $\mathrm{Gy} / \mathrm{MBq}^{\mathrm{a}}$ & $\mathrm{Sv} / \mathrm{MBq}$ \\
& $\mathrm{w}_{\mathrm{R}}=5$ & $\mathrm{w}_{\mathrm{R}}=20$ \\
\hline Red marrow & 0.15 & 0.59 \\
Endost-BS & 1.08 & 4.22 \\
Liver & 0.17 & 0.68 \\
Kidneys & 0.11 & 0.43
\end{tabular}

${ }^{\mathrm{a}} \mathrm{Gy}$ indicates an RBE-weighted absorbed dose for deterministic biological effects [17]; Endost-BS, endosteum bone surface

\section{Discussion}

Biodistribution

In the last years clinical trials using the radiopharmaceutical Xofigo $\AA^{\circledR}$ were undertaken to derive the distribution of ${ }^{223} \mathrm{Ra}$ in the human body [5-8]; the pharmacokinetics were obtained by gamma scintigraphy of the whole body. An overview of the results of these studies is presented in Table 3 together with the results of the compartmental modelling study developed for this work. Parts of the results of the present work are in good agreement with the results of the clinical trials: very fast plasma clearance, main uptake into bone (although by different proportion), small urinary excretion and large activity in the colon with main excretion of ${ }^{223} \mathrm{Ra}$ in the faeces. The faeces' excretion rates of the patients are rather variable because of the inter-individual metabolic differences and the high 
variability in intestinal transit times [5]. In studies of Chittenden et al. [7], for example, activities of

${ }^{223} \mathrm{Ra}$ in the small intestine are observed $4 \mathrm{~h}$ after intravenous administration, whereas the biokinetic model of ${ }^{223}$ Ra predicted by the ICRP does not include a specified compartment for Small Intestine. Remarkable is, however, the increased initial uptake of ${ }^{223} \mathrm{Ra}$ into the bones of patients as reported in clinical studies $[5,7]$, which is stated to be about $50-60 \%$, compared to the modelled $30 \%$ after $4 \mathrm{~h}$ of injection. Taprogge et al. [26], who analysed data of six patients from Chittenden et al. [7], are in the process of developing a simple compartmental model for plasma, bone surfaces, small and large intestines, and excretion path that better fits to the patient data. Carrasquillo et al. [8] observed a small amount (not quantified) of activity in kidneys and liver, but only early after injection $(<4 \mathrm{~h}$ postadministration). In the present simulation, a low distribution of ${ }^{223} \mathrm{Ra}$ in liver and kidneys was observed at early times after administration (Fig. 4). In other organs and tissues, both the clinical data and our modelled data showed no significant distribution of ${ }^{223} \mathrm{Ra}$ and its progeny.

Organ absorbed and equivalent doses

The importance of patient dosimetry in radionuclide therapy and its limitations have been recognized by many authors and reviewed by Lassmann and Eberlein [27]. The present work is reporting recent developments combining new biokinetic and dosimetric modelling.

The results of the present work are summarised in the Tables 4-6 showing the calculated organ absorbed and equivalent doses for a reference adult male (73 kg, $176 \mathrm{~m}$ height) after administration of ${ }^{223} \mathrm{Ra}$. The highest absorbed doses were found in the bone endosteum, liver, red marrow, and kidneys. Mainly alpha particles emitted from ${ }^{223} \mathrm{Ra}$ and its progeny deposit the absorbed dose in these organs; the isotopes ${ }^{219} \mathrm{Rn},{ }^{215} \mathrm{Po}$, and ${ }^{211} \mathrm{Bi}$ contribute most to the dose. Similar contribution of the ${ }^{223} \mathrm{Ra}$ progeny to bone lesion-absorbed doses was found in the study of Murray et al. [25]. The calculated dose coefficients for bone endosteum, red marrow and colon were lower than clinical data reported by Yoshida et al. [5] and Chittenden et al. [7]. The authors of these studies evaluated clinical imaging data, and derived the cumulated activities through region of interests (ROIs). For the dosimetry, the dosimetric tool OLINDA/EXM [28] was used, software based on the MIRD algorithm and SAFs derived on mathematical phantoms. The calculated kidneys and liver doses of this work were higher compared to those revealed by the clinical studies. It should be noted, that, data 
stemming from clinical studies cannot be compared directly with compartmental modelling calculations, as a specific tumour dosimetry is not included in these models [24].

The results of the present study were compared to the results of the compartmental modelling of Lassmann and Nosske [23] and were found to be lower (skeletal doses by a factor of 2.3-3.4, colon dose by a factor of 7.5), except for the doses to liver and kidneys, which were found to be higher by a factor of ca. 7. The discrepancies of dose coefficients may be due to the different pharmacokinetic models of radium applied. In this work, the new ICRP biokinetic model for ${ }^{223} \mathrm{Ra}$ [10] was used whereas Lassmann and Nosske used the previous ICRP model of ${ }^{223} \mathrm{Ra}$ [23]. The latter model for radium consisted of only one liver compartment and had no specific kidney compartment. Further, the gastrointestinal tract (see ICRP 30, [22]) included the compartments upper large intestine (ULI) and the lower large intestine (LLI); there was no subdivision into the compartments right colon (RC), left colon (LC), and the recto sigmoid (RS), as per the HATM [15]. In addition, many transfer rates of the old ICRP radium model and its progeny were different compared to the new ICRP ${ }^{223} \mathrm{Ra}$ model and its progeny. For example, in the old radium model, the transfer coefficient from the compartments Blood to Liver 1 was $0.35 \mathrm{~d}^{-1}$, whereas in the new radium model this value was increased to $4.2 \mathrm{~d}^{-1}$.

Moreover, the dosimetric framework of ICRP Publication 133 [13] used for the present work, presents several improvements in comparison to the former system [22] employed by dosimetric software tools used by Lassmann and Nosske [23] and clinical studies: the majority of SAF values are derived from Monte Carlo radiation transport simulations in the ICRP reference adult computational phantoms [19]. For the skeletal dosimetry, which is of primary importance for this work, computational algorithms are applied to relate the absorbed dose to spongiosa and medullary marrow to the absorbed dose to either endosteum or red marrow. For the models for alpha particle transport, the reader is referred for more details to [13]. Additional values of alpha and electron SAFs are taken from ICRP Publication 66 [29] for the Human Respiratory Tract Model (HRTM), with changes consistent with revisions to the HRTM presented in Publication 130 [30]. New values of alpha and electron SAFs are given for the HATM Model in [13] that supersede those given in Publication [15].

After a simulated series of six treatments of $55 \mathrm{kBg} / \mathrm{kg}$ of ${ }^{223} \mathrm{Ra}$ injected per treatment, which is often the recommended dosage to patients, and for the body mass of $73 \mathrm{~kg}$ [31], the bone surface dose would amount, according to the present study, to 5.21 Gy and the red marrow dose to 0.78 Gy, 
respectively. Findings of clinical studies reviewed by Flux [32], reported much higher values of absorbed doses in bone surface and in red marrow, in the range of 54 Gy to $303 \mathrm{~Gy}$, and from 4 Gy to 23 Gy, respectively. Similarly, Lassmann and Nosske [23] calculated absorbed doses of 16 Gy, and 1.7 Gy in bone surface and red marrow, respectively, after a simulated series of six treatments of each $50 \mathrm{kBq} / \mathrm{kg}{ }^{223} \mathrm{Ra}$, for the body mass of $70 \mathrm{~kg}[22]$.

Moreover, there are two clinical studies for which quantitative imaging for dose estimation in metastatic bone lesions was applied: Pacilio et al. [33] presented absorbed doses to bone lesions of 0.2-1.9 Gy after a single injection of $50 \mathrm{kBq} / \mathrm{kg}{ }^{223} \mathrm{Ra}$ to patients. However, it was not clear whether the ${ }^{223} \mathrm{Ra}$ activity measured affected directly the bone lesions or only bone regions with high activity surrounding the metastasis. A study of Murray et al. [25] showed a wide range of absorbed doses across multiple sites of lesions (0.6-44.1 Gy) after a single administration of $110 \mathrm{kBq} / \mathrm{kg}{ }^{223} \mathrm{Ra}$. According to the present work, absorbed dose of 0.87 Gy in the endosteum bone surface is estimated after a single simulated injection of $55 \mathrm{kBq} / \mathrm{kg}{ }^{223} \mathrm{Ra}$, which is in agreement to the dose range reported by Pacilio et al. [33].

The comparison of the absorbed dose values estimated from modelling with values stemming from quantitative imaging in the clinic practice is difficult as there are large uncertainties in dose calculations based on imaging. Possibly, the limited count rates in imaging of ${ }^{223} \mathrm{Ra}$ in liver and kidneys might explain the low dose coefficients estimated from quantification imaging compared to the much higher dose calculations in liver and kidneys of the present compartmental modelling. Flux [32] discussed in his review the challenges in dosimetry: the heterogeneous uptake of the ${ }^{223} \mathrm{Ra}$ (Xofigo®) in tissues and organs of patients, the difficulties to correctly determine the ROls (region of interest) from the images and the quantification of ${ }^{223} \mathrm{Ra}$ activities in the organs or tissues, the difficulties to estimate the time-integrated activity curves, or to assess lesion volumes. Additionally, a high variability of the patients and different clinical techniques for imaging and dose calculations in the different clinics may lead to propagation of uncertainties in dose assessments from radiopharmaceutical application of ${ }^{223} \mathrm{Ra}$.

\section{Conclusion}


The radiopharmacokinetic modelling of ${ }^{223} \mathrm{Ra}$ and its progeny can help to predict their distribution in

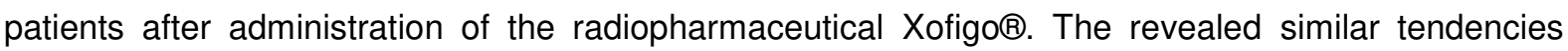
concerning the plasma clearance and excretion via urine and faeces and highest uptake in bone of the modelled ${ }^{223} \mathrm{Ra}$ data compared to the clinical data showed the feasibility of applying the newly reported ICRP biokinetic models in clinical trials. However, the dose coefficients in organ and tissues presented in this work showed discrepancies to the values from the clinical studies and of another modelling study. The skeletal doses were found to be lower by a factor of 2.3-3.4 than previously calculated. The differences in dose calculation might result from the application of different biokinetic ICRP models for ${ }^{223}$ Ra and its progeny, ICRP Publication 137 [9] vs Publication 67 [10]. Moreover, the dosimetry system used for this work, as described in ICRP Publication 133 [13], is in many aspects different than the dosimetry system used for earlier studies. The use of SAF values based on the methodology of ICRP Publication 133 [13] has a great impact on doses to the endosteum, red bone marrow and colon. In conclusion, this study provides a framework of dose assessment on Xofigo ${ }^{\circledR}$ administered to patients. It utilises the most state-of-the-art biokinetic and dosimetric models available and dose coefficient values derived from a reference anthropomorphic male computational voxel phantom and detailed mathematical phantoms for modelling of fine structures. Further clinical imagebased activities in organs and tissues are needed to validate and improve these theoretical values.

\section{Declarations}

Ethics approval and consent to participate

Not applicable

\section{Consent for publication}

Not applicable

\section{Availability of data and materials}

The data used and evaluated during the current study are available from the corresponding author on reasonable request.

\section{Competing interests}

The authors declare that they have no competing interests. 


\section{Funding}

This work was supported by the Helmholtz Zentrum München - German Research Canter for Environmental Health $(\mathrm{GmbH})$.

\section{Author contributions}

All authors contributed to the study planning, data acquisition and analysis. Vera Höllriegl wrote the first draft of the manuscript, which has been revised by Nina Petoussi-Henss and Wei Bo Li. All authors have approved the final manuscript.

\section{Acknowledgements}

Authors thank Augusto Giussani for his valuable support in discussing the biokinetics of radium and its progeny.

\section{References}

1. Bray F, Ferlay J, Soerjomataram I, Siegel RL, Torre LA, Jemal A. Global Cancer Statistics 2018: GLOBOCAN Estimates of Incidence and Mortality Worldwide for 36 Cancers in 185 Countries. CA Cancer J Clin. 2018;68:394-424.

2. EMA. Human medicine European public assessment report (EPAR): Xofigo. European Union; 2018. http://www.ema.europa.eu/medicines/human/EPAR/xofigo.

3. Macedo F, Ladeira K, Pinho F, Saraiva N, Bonito N, Pinto L, et al. Bone Metastases: An Overview. Oncology Reviews. 2017;11:321.

4. Parker C, Nilsson S, Heinrich D, Helle SI, O'Sullivan JM, Fossa SD, et al. Alpha Emitter Radium223 and Survival in Metastatic Prostate Cancer. N Engl J Med. 2013;369:213-23.

5. Yoshida K, Kaneta T, Takano S, Sugiura M, Kawano T, Hino A, et al. Pharmacokinetics of single dose radium-223 dichloride (BAY88-8223) in Japanese patients with castration-resistant prostate cancer and bone metastases. Ann Nucl Med. 2016;30:453-60.

6. Pratt BE, Hindorf C, Chittenden SJ, Parker CC, Flux GD. Excretion and whole-body retention of radium-223 dichloride administered for the treatment of bone metastases from castration resistant prostate cancer. Nucl Med Commun. 2018;39:125-30.

7. Chittenden SJ, Hindorf C, Parker CC, Lewington VJ, Pratt BE, Johnson B, et al. A Phase 1, open-label study of the biodistribution, pharmacokinetics and dosimetry of Radium-223 dichloride $\left({ }^{223} \mathrm{Ra}\right.$ dichloride) in patients with hormone refractory prostate cancer and skeletal metastases. J Nucl Med. 2015;56:1304-9.

8. Carrasquillo JA, O'Donoghue JA, Pandit-Taskar N, Humm JL, Rathkopf DE, Slovin SV, et al. Phase 1 pharmacokinetic and biodistribution study with escalating doses of ${ }^{223}$ Ra-dichloride in men with castration-resistant metastatic prostate cancer. Eur J Nucl Med Mol Imaging. 2013;40:1384-93. 9. ICRP. Occupational Intakes of Radionuclides: Part 3. In: Sage, editor. ICRP Publication 137: International Commission of Radiological Protection; 2017.

10. ICRP. Age-dependent doses to members of the public from intake of radionuclides: Part 2: Ingestion dose coefficients. ICRP Publication 67. Oxford, UK: Pergamon Press; 1993.

11. Nilsson S, Larsen RH, Fossa SD, Balteskard L, Borch KW, Westlin J-E, et al. First Clinical Experience with a-Emitting Radium-223 in the Treatment of Skeletal Metastases. Clin Cancer Res. 2005;11:4451-9.

12. Bolch WE, Eckerman KF, Sgouros G, Thomas SR. MIRD Pamphlet No. 21: A Generalized Schema for Radiopharmaceutical Dosimetry-Standardization of Nomenclature. J Nucl Med. 2009;50:477-84. 
13. ICRP. The ICRP computational framework for internal dose assessment for reference adults: specific absorbed fractions. In: Clement $\mathrm{CH}$, editor. ICRP Publication Oxford, UK: International Commission of Radiological Protection; 2016. p. 1-74.

14. ICRP. Nuclear decay data for dosimetric calculations. In: Elsevier, editor. ICRP Publication 107. Oxford, UK: International Commission of Radiological Protection; 2008.

15. ICRP. Human alimentary tract model for radiological protection. ICRP Publication 100. Oxford, UK: Elsevier; 2006.

16. Barrett PH, Bell BM, Cobelli C, Golde H, Schumitzky A, Vicini P, et al. SAAM II: Simulation, Analysis, and Modeling Software for tracer and pharmacokinetic studies. Metabolism. 1998;47:484-

92.

17. ICRP. The 2007 Recommendations of the International Commission on Radiological Protection. In: Protection ICoR, editor. ICRP Publication 103. Oxford, UK: Elsevier; 2007.

18. Sgouros G, Roeske JC, McDevitt MR, Palm S, Allen BJ, Fisher DR, et al. MIRD Pamphlet No. 22 (Abridged): Radiobiology and Dosimetry of $\alpha$-Particle Emitters for Targeted Radionuclide Therapy. J Nucl Med. 2010;51:311-28.

19. ICRP. Adult reference computational phantoms. In: Elsevier, editor. ICRP Publication 110. Oxford, UK: International Commission on Radiological Protection; 2009.

20. Ocampo Ramos JC. Dose evaluation by incorporation of radionuclides: proposed database and software for nuclear medicine: National University of Colombia - Medellín campus; 2016.

21. Petoussi-Henss N, Ocampo Ramos J, ZankI M, Li WB, Rühm W. Voxel based internal dosimetry of radiopharmaceuticals in diagnostic nuclear medicine. Annual Congress of the European Association of Nuclear Medicine EANM'17. Vienna, Austria: Eur J Nucl Med Mol Imaging; 2017. p. S119-S956.

22. ICRP. Limits for Intakes of radionuclides by Workers. Part 2. ICRP Publication 30. Oxford, UK: Pergamon Press; 1980.

23. Lassmann M, Nosske D. Dosimetry of 223Ra-chloride: dose to normal organs and tissues. Eur J Nucl Med Mol Imaging. 2013;40:207-12.

24. Lassmann M, Eberlein U. Targeted alpha-particle therapy: imaging, dosimetry, and radiation protection. Ann ICRP. 2018;47:187-95.

25. Murray I, Chittenden SJ, Denis-Bacelar AM, Hindorf C, Parker CC, Chua S, et al. The potential of ${ }^{223} \mathrm{Ra}$ and ${ }^{18} \mathrm{~F}$-fluoride imaging to predict bone lesion response to treatment with ${ }^{223} \mathrm{Ra}$-dichloride in castration-resistant prostate cancer. Eur J Nucl Med Mol Imaging. 2017;44:1832-44.

26. Taprogge J, Murray I, Gear J, Chittenden SJ, Parker CC, Flux GD. Compartmental Model for

${ }^{223}$ Ra-Dichloride in Patients With Metastatic Bone Disease From Castration-Resistant Prostate Cancer. International Journal of Radiation Oncology Biology Physics. 2019;105:884-92.

27. Lassmann M, Eberlein U. The Relevance of Dosimetry in Precision Medicine. J Nucl Med. 2018;59:1494-9. doi:10.2967/jnumed.117.206649.

28. Stabin MG, Sparks RB, Crowe E. OLINDA/EXM: The Second-Generation Personal Computer Software for Internal Dose Assessment in Nuclear Medicine. J Nucl Med. 2005;46:1023-7.

29. ICRP. Human respiratory tract model for radiological protection. ICRP Publication 66.

Oxford, UK: Pergamon Press; 1994.

30. ICRP. Occupational Intakes of Radionuclides: Part 1. In: Elsevier, editor. ICRP Publication 130. Oxford, UK: Pergamon Press; 2015.

31. ICRP. Basic anatomical and physiological data for use in radiological protection: reference values. ICRP Publication 89. Oxford, UK: Pergamon Press; 2002.

32. Flux G. Imaging and dosimetry for radium-223: the potential for personalized treatment. Br J Radiol. 2017;90:20160748.

33. Pacilio M, Ventroni G, De Vincentis G, Cassano B, Pellegrini R, Di Castro E, et al. Dosimetry of bone metastases in targeted radionuclide therapy with alpha-emitting ${ }^{223}$ Ra-dichloride. Eur J Nucl Med Mol Imaging. 2016;43:21-33. 


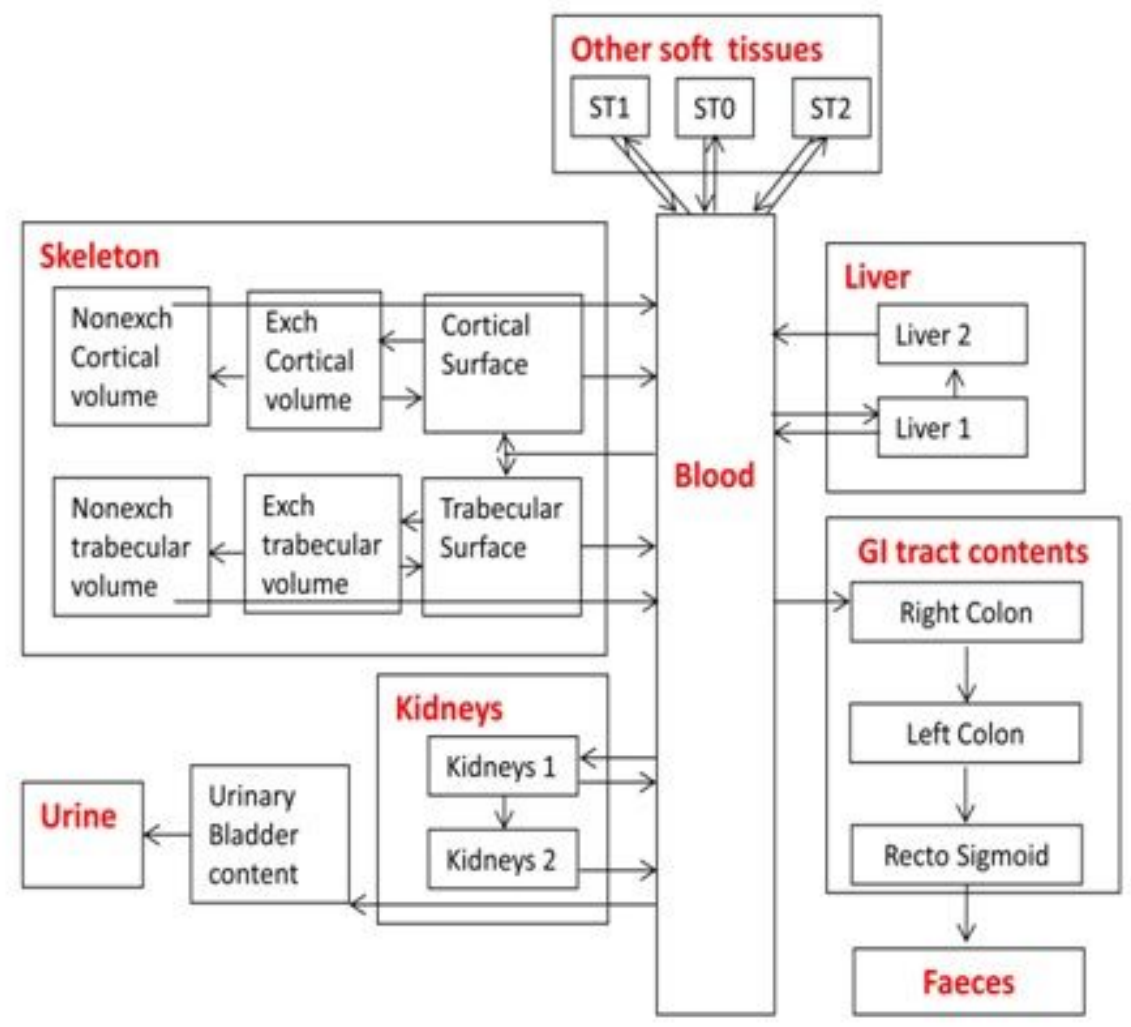

\section{Figure 1}

Systemic model of 223Ra, according to ICRP 137 (2017) [9]

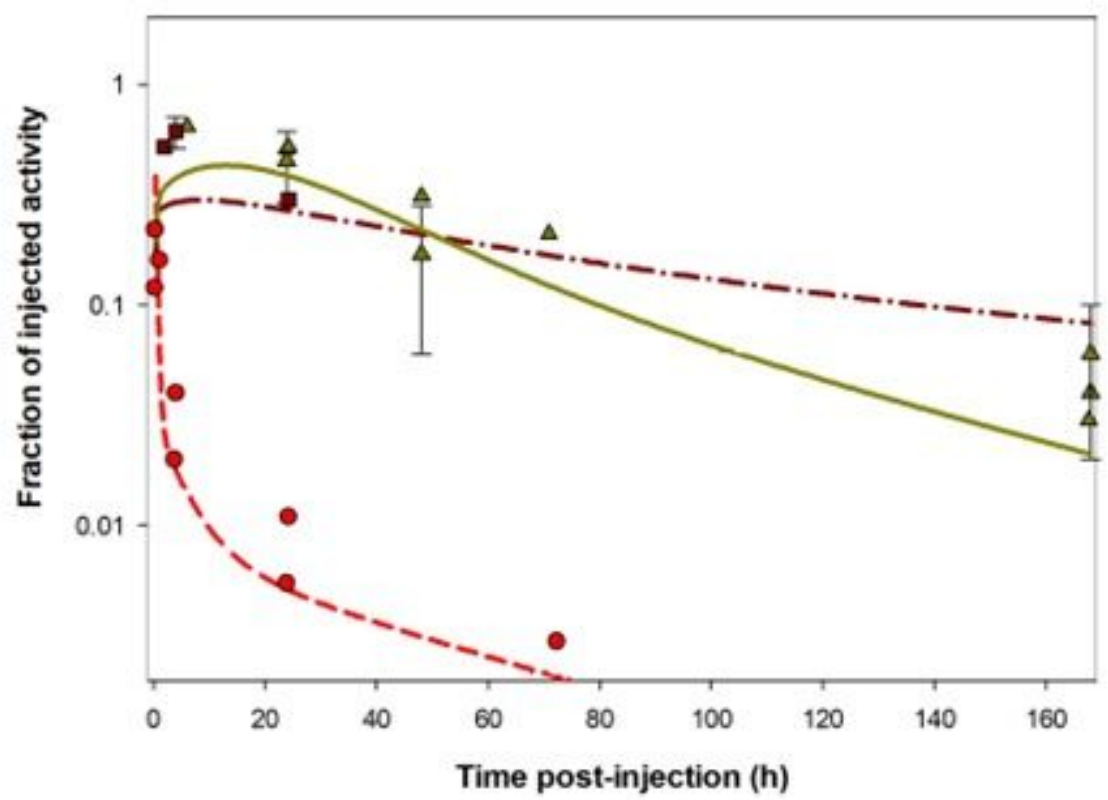

Figure 2 
Time-dependent distribution of 223Ra in plasma, bone and colon after intravenous injection. Dashed Line $=$ modelled data of plasma, solid line $=$ modelled data of colon, dash-dotted line $=$ modelled data of bones. Bullets = plasma data of patients, squares $=$ bone data of patients, triangles = colon data of patients. Patient data from $[5,7,8,11]$ shownwith median values or values of mean $\pm S D$. Bone indicates total bone i.e. cortical, trabecular surface, volume and marrow.

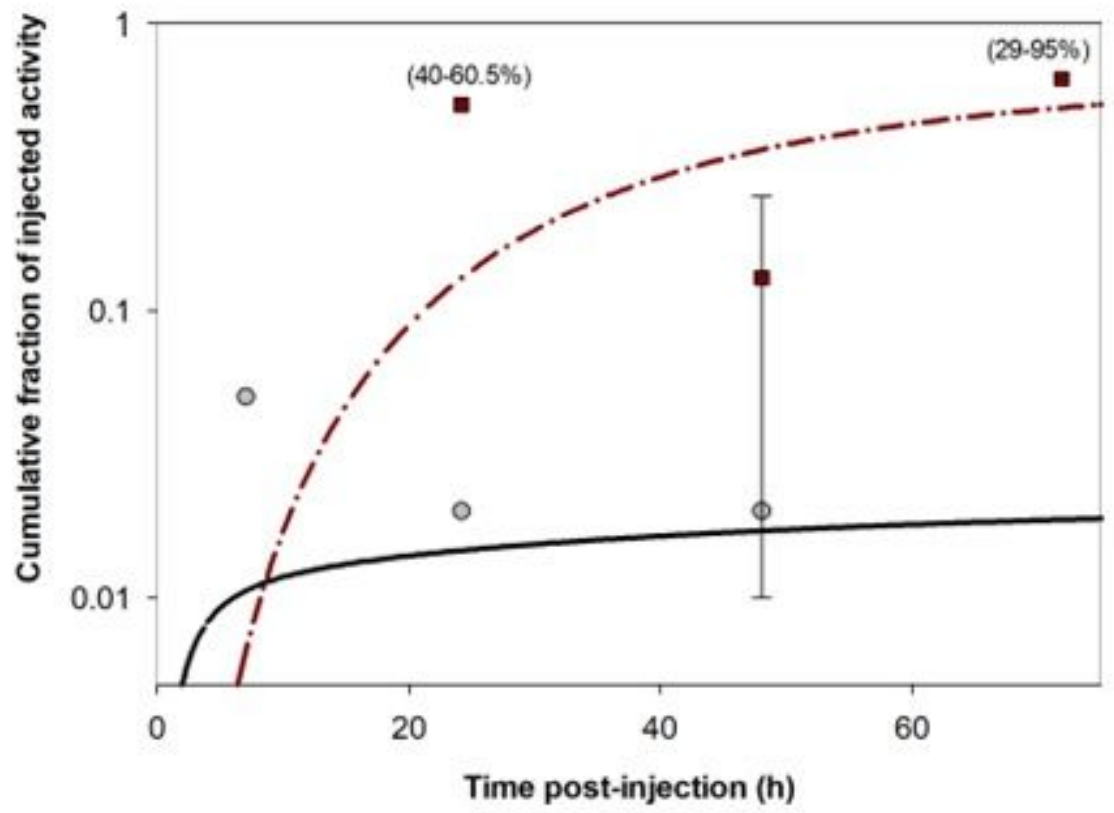

\section{Figure 3}

Time-dependent excretion of 223Ra after intravenous injection. Dash-dotted line = modelled data of faeces, solid line $=$ modelled data of urine; squares $=$ faeces data of patients, bullets $=$ urine data of patients. Patient data from $[5,7,8,11]$ shown with mean values or mean $\pm S D$, or ranges (in parentheses) 


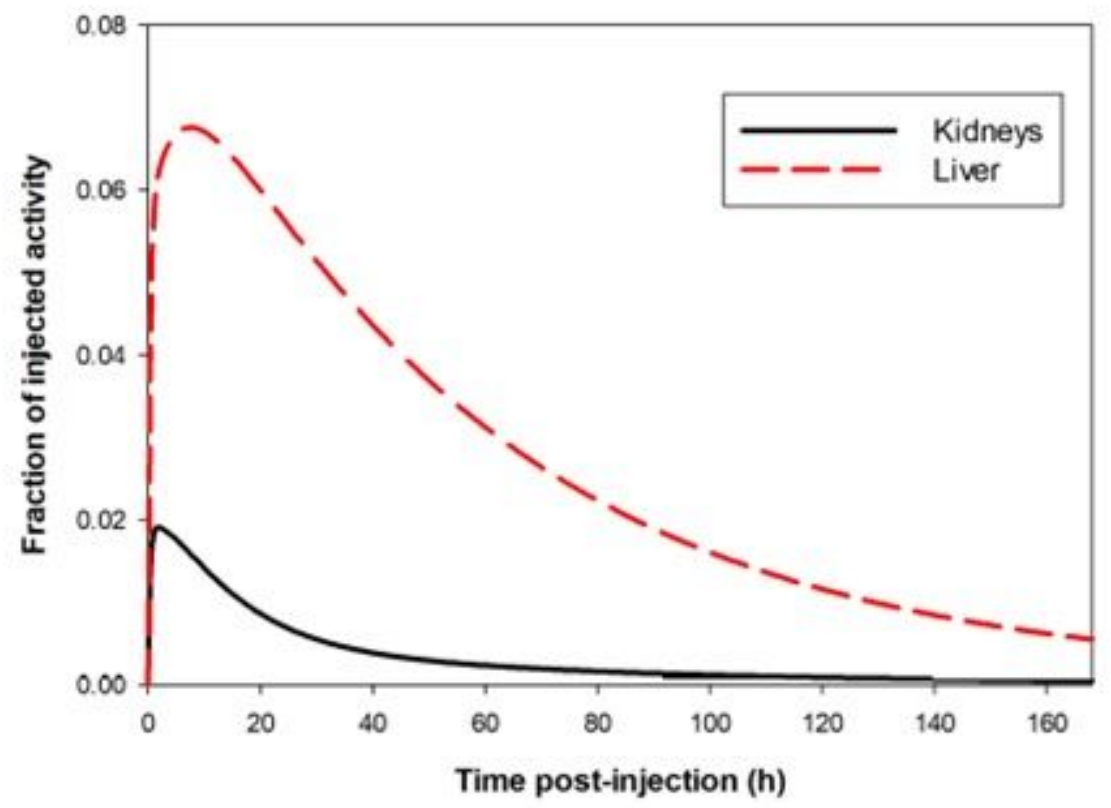

Figure 4

Modelled time-dependent distribution of 223Ra in kidneys and liver after intravenous injection 